\title{
Home or Office: \\ Technology, Attitude, and At-Home Work
}

by David Levinson

December 19, 1996 


\section{ABSTRACT}

This paper examines the influence of technology and employer attitude on the decision to work at home. Using data from a suburban Washington household travel survey, it is found that both technology and a favorable employer attitude are positively associated with the number of hours and days in a two week period during which a respondent works at home. Other factors, including demographics, socio-economics, commuting time, and employer type were not statistically significant. Log-linear and translog forms were better fits than a simpler linear form. 


\section{INTRODUCTION}

Telecommuting and the decision to work at home have long held the promise of being able to solve much of the peak congestion problem. If workers cease to commute to work on a daily basis with a fixed schedule, the peaking of traffic which strains the urban transportation network will diminish. In this vision, communication technologies substitute for transportation. Levinson and Kumar (1995), confirming to some degree this suggestion, found that individuals in the Washington area who work at home travel less (64 minutes per day) than those who work outside the home (98 minutes) or those who don't work at all (84 minutes). However, the amount of nonwork travel by those who work at home is more than that of commuters: relaxing the amount of commuting increases the amount of other travel. It is therefore likely that communications and information technology serve as both substitutes and complements transportation at the same time. However, while the substitution is direct, the complementarity is due to a reduction of the constrained resource, the time available for nonwork travel.

The adoption of personal computers and related technologies in the home in the 1990's appear to be following their emergence on the desk of nearly every office worker in the 1980's. By 1994, home computers were found in 32 million United States homes and almost 7 million home computers are sold each year (Bryant 1994). As computers and related telecommunication technology are necessary, if not sufficient, criteria for performing office work at home, this trend of technology adoption should enable an increase in the amount of work at home. Clearly, for most people, present technology does not permit at-home work to be a perfect substitute for office work. Communication is still slow or expensive, video cannot be easily transmitted, and personal interaction is therefore limited to voice communications, occasional courier, limited data transfer, fax, and e-mail.

This paper investigates the influence of computer technology on the decision to work at home. No attempt is made at determining causality: Does someone decide to work at home after he has acquired computer equipment, or does he acquire the computer in order to work at home? The paper estimates a model to explain the amount of time worked at home. The hypothesis is that home computer technology will enable individuals to work at home more than those who don't. Technology is thus viewed as a necessary but not sufficient condition for at-home work in the information age.

The opposite hypothesis states that technology will encourage workers to spend more time at the office. Evidence suggests businesses adopt advanced technology earlier 
than homes, so being away from the office will be a handicap. If the power of technology is growing at an accelerating pace, the technological capabilities of the home will fall farther and farther behind that of the office. Two views of technology, where the home catches up with the office, or where the exponential growth in technology causes the office to be increasingly more advanced than the home, are illustrated in figures 1 and 2.

In fact, both hypotheses could be true if technology, instead of reducing the amount of work, rather increases it. Schor (1991) argues that the amount of time spent at work per worker per week has steadily increased in the latter half of the twentieth century. This has been over a period with ever increasing technology and shifts from an industrial to an information economy.

Many previous studies have investigated work at home and telecommuting behavior through specific telecommuting pilot projects (Mokhtarian 1991; Kitamura et al. 1991). Further, the federal government has sponsored several reviews of the subject (DOT 1993; Niles 1994). This study takes a somewhat different approach by investigating at home work among the general population using a cross-sectional survey.

This study is conducted using data from Montgomery County, MD. Montgomery County is a large suburban jurisdiction to the immediate north of Washington D.C. In 1990 the county had 750,000 residents living in 280,000 household. The number of jobs in the county was estimated at 410,000 . The county is characterized by high incomes, it was among the top ten of highest per capita income counties in the United States in 1990. The employment is geared towards the federal government, with a large number of office workers and among the highest proportion of scientists and engineers of any area in the country. Government related industry dominates the area, including a large biotech industry as well as defense oriented companies.

After describing the data used in this study is a description of various model structures to describe work at home. The hypotheses tested are presented, followed by linear regressions testing them using several functional forms, and then their economic interpretation. The paper concludes with some policy implications and needs for further research.

\section{DATA}

Wave 1 of the Montgomery County Travel Panel Survey (conducted in 1991) is the first phase of what is intended to be a multi-year longitudinal survey garnering in- 
depth information about the travel behavior of a panel of Montgomery County residents (Kumar and Replogle, 1992; MCPD, 1993). Wave 1 was conducted as a mail out-mail back survey with both demographic and travel diary components. Responses from 600 persons include 410 workers studied here. Analysis of individual and household behavior before and after acquiring various states of technology using future waves of this survey will enhance the understanding of causality in this critical issue. The survey asks one question (of individuals who are workers) concerning at home work:

During the past two weeks, how much time did you work at home?

Ave Hrs./Day _ _ No. of Days__ Never

From this is obtained the dependent variables of HOURS (which is the Ave. Hrs/Day multiplied by No. of Days) and DAYS (which is the No. of Days) used later. For the sample of 410 workers, the average number of hours in the two week period worked at home was 3.1, and the average number of days was 0.7 . In retrospect, the wording of the question is somewhat ambiguous, some individuals provided the Ave. Hrs/Day but not the No. of Days, for them, the number of days was imputed to be 10 (the typical number of work days in a two week period). No-one responded by answering No. of Days without the Ave Hrs/Day. Those who answered Never did not provide a response to the other two choices, which is consistent with what was desired. It is not expected this ambiguity will alter the general findings of the paper.

The survey also asks of all individuals the computer equipment at home:

What facilities do you use at home?

_ Computer __ Printer__ Fax

_ Modem _ Copier

Of the 410 workers in the survey, Table 1 shows the frequency of each piece of equipment. Computers were used by $36 \%$ of the individuals at home, printers by $27 \%$, fax machines by $2 \%$, modems by $14 \%$, and copiers by none of the sample. Due to the income, education level, and information sector orientation of Montgomery County, these figures for Montgomery in 1991 were probably above national averages.

\section{MODEL STRUCTURE}

The work location decision is a complex function of many inter-related factors. Once it is determined if an individual is a worker, the location decision arises. Work location (home or office) may depend on whether the job is full or part-time, who is the 
employer and their attitude, the number of hours per day and the number of days per week that one works, the degree of social interaction required on the job, the generalized cost of traveling to work, the quality of housing, life-cycle stage, and the technology available at both the home and the office. In other words, to what extent do the home and office provide comparable production technologies for work?

In the abstract, what is desired is a general model of work-activity decisions, from which can emerge behaviors including both traveling to a distant worksite (the typical commute) as well as working at home, along with any other, possibly uncontemplated choices, such as the emergence of work while commuting via the use of car phones and portable computers on trains and airplanes.

Short of that, it may be possible to model the communications/transportation trade-off for work activity. Many key factors in the decision of any individual about how much to commute and how much to telecommute are probably hidden, but some general hypotheses may be put forward. The decision to travel to work indicates that the utility of physical presence due to both human interaction and the availability of certain technological attributes outweighs the cost of travel, child care, eating out, etc. and the inefficiency due to disruptions in the office. Staying at home suggests the opposite. These decisions may be dictated by the employer rather than the employee in some cases, wherein the employer, acting through a manager, demands physical presence even though the employee might think it unnecessary. In the future, to save on rent, the employer might demand that an employee work at home, and only come in to the office occasionally. Over the course of time, the key question is what mix of work at home vs. work outside the home will occur on an hour to hour, day to day, and week to week basis.

The following lists some of the advantages and disadvantages of working outside the home. The advantages of working at home are the disadvantages of working outside the home, and vice versa.

\section{Working Outside the Home}

Advantages

Direct human interaction

Quality of office equipment

Getting out of the house

Less home space required $\underline{\text { Disadvantages }}$

Cost of travel

Cost of child-care

Distraction

More office space needed

? <-- Higher productivity --> ? 
These factors are implicitly accounted for by the employer and employee when individually and jointly deciding the home vs. outside-the-home workplace decision. Future research should try to include these factors explicitly.

\section{HYPOTHESES}

Several hypotheses are tested in this study. The first concerns the expected positive influence of technology ownership and the amount of time spent working at home. Table 1 shows the average number of hours and number of days worked at home depending on which pieces of computer/communications equipment are owned. Table 2 shows a similar result using an ordinal index called "TECH", which is simply the sum of the number of pieces of the above equipment owned. This composite index is used rather than the individual pieces of equipment to avoid problems due to the obvious correlation of ownership among computers and peripherals. If none is owned then $\mathrm{TECH}=0$, if only a computer then $\mathrm{TECH}=1$, if a computer and a printer or a computer and modem then $\mathrm{TECH}=2$, and so on. A clear trend is visible - the more equipment, the more hours and days worked at home. The explanation is that, for many, an electronic home office may be prerequisite to working at home. However, as noted earlier, cause and effect are not clear here: does someone own computer equipment, and then decide "now I can work at home" or does she decide "I want to work at home, I need to get a computer (fax, copier)".

A second set of hypotheses relate to demographic and socioeconomic variables. Gender is thought to be important based on previous research. Levinson and Kumar (1995) found that for metropolitan Washington in 1988, women work at home more than men (nearly $4 \%$ of the females and only $1 \%$ of the males work at home and not outside the home on any given day). The speculated rationale had to do with small female owned businesses operating out of the home. This trend is reaffirmed in this data, Table 3 shows hours worked at home by gender, females spent more time at home than males, although the standard deviation is large. The dummy [1,0] variable MALE, "1" indicating the respondent is male, " 0 " if female, is thus expected to be negatively (and significantly) related to the amount of time spent working at home in the past two weeks.

The question on household income in the survey was not comprehensively answered, so other surrogates are tested as substitutes to reflect income. These are the continuous variable household vehicle ownership (VEH) and the binary variable for dwelling unit type (SFHOME), "1" indicating the respondent lives in a single family 
(attached or detached) home, "0" indicates otherwise (generally apartments). Income is thought to be positively associated with information age employment, as well as consultant type careers, which may be more conducive to work at home. In the crosstabulations of means of hours worked by vehicle ownership (Table 4), the results are ambiguous, but for single family home ownership (Table 5), it would appear positive. However, due to the large standard deviations, these differences may not be statistically significant. The SFHOME variable may also reflect the capacity to work at home because of space requirements, houses are larger than apartments and more likely to have an extra room which can be used for an office.

Employer attitude should be important as reflected in Table 6. Two binary [1,0] variables are used: SWAH and AWAH, which reflect whether the employer allows the worker to sometimes or always. Sometimes Work At Home (SWAH) takes a value 1 if sometimes, 0 if otherwise (never or always). Always Work At Home (AWAH) takes a value of 1 if the employer always allows the worker to work at home, 0 if otherwise (never or sometimes).

Next, it is hypothesized that the home to work commuting time should be positively associated with working at home. The greater the time spent commuting to work, the more often one will try to find a substitute (namely work at home). The mean commuting time for those work at home more than 4 hours at a time is longer (37 minutes) than the general sample (33 minutes).

Last the nature of the work may also have some effect on this decision. Workers were asked if they worked for the private sector, government (GOV), a non-profit organization (NPO) or were self-employed (SELF). These were translated into three binary variables. As suggested by Table 7, it is posited that self-employed workers will be most likely to also work at home.

\section{RESULTS}

This section reviews the results of several Ordinary Least Squares regressions reflecting linear, logarithmic, and translog forms. Table 8 shows the linear regressions for hours and for days in the past two weeks. The basic hypothesis concerning the level of technology being positively associated with time working at home is borne out. The variable TECH is positive and significant for both HOURS and DAYS. However, the overall predictive value of this model form is weak, explaining only $15 \%$ of the variance in the data for HOURS and $12 \%$ for DAYS. Moreover, aside from AWAH and SWAH representing employer attitude, none of the other variables were statistically significant. 
This suggests that factors influencing this uncommon and irregular behavior have not been captured in this regression. In addition, an alternative model form may work better.

Why weren't VEH and SFHOME significant? It is possible that TECH is a better indicator of income then VEH because in suburban Montgomery County, vehicle ownership has reached near saturation levels, so the additional cars owned may not predictably reflect income, while higher income may be related to more rapid technology adoptions. Similarly, a large proportion of the county's residents live in single family homes, so perhaps not much differentiation is obtained.

Table 9 shows two regressions which convert the above variables into a logarithmic form to test whether this transform improves the predictive power. The dependent is the natural $\log$ of hours +1 (and the natural $\log$ of days +1 ). The " +1 " in the variables was used to eliminate the problem of $\ln (0)$ being undefined, while the $\ln (1)$ equals 0 , which is what is desired. For HOURS the adjusted R Square increases from .15 to .26 with this transform, and the significance of the technology and SWAH and AWAH variables increase. Similarly the regression for DAYS has the adjusted R Square rise from .12 to .22 . However, the other independent variables in this regression remain insignificant.

Table 10 shows a simplified model, excluding all of the statistically insignificant variables. In addition, the attitude variables (SWAH and AWAH) have been combined into a single variable: combined work at home (CWAH), which takes the value of 0 if the employer never allows the employee to work at home, 0.5 if sometimes, and 1 if always. This is an implicit scaling of the relative importance of these two responses. Clearly, attitude is a continuum which should be represented that way. But whether "sometimes" is one-half of "always" is a judgement. This model has a higher R-square than the more comprehensive models in Table 9, with R-Square $=0.42$ for predicting hours and 0.37 for predicting days.

Last, Table 11 shows a translog form of this simplified model, adding a term reflecting the possibly synergistic interactions of employer attitude with technology. The translog model is given by the following equation:

$$
\ln (\mathrm{Y})=\ln \mathrm{a}_{0}+\sum \mathrm{a}_{\mathrm{i}} \ln (\mathrm{Xi})+0.5 * \sum \sum \mathrm{a}_{\mathrm{ij}} \ln \left(\mathrm{X}_{\mathrm{i}} \mathrm{X}_{\mathrm{j}}\right)
$$

This model shows slightly improved explanatory power, the adjusted R-Square rising to 0.44 and 0.38 for hours and days respectively. However, while the interaction term is statistically significant, the technology term alone ceases to be. 


\section{ECONOMIC INTERPRETATION}

The model in Table 10 is discussed further. It takes the Cobb-Douglas form and can be thought of as a production model, where "work at home" is being produced and the two factors of production are technology and attitude. This concept of work production differs somewhat from Becker's (1965) use of household production, wherein household members used money and time to produce commodities generating utility, these commodities are for example sleep, which requires 8 hours of time and a bed. From this model, the returns to scale and the marginal product of factors can be seen.

Returns to scale describe the rate at which output changes relative to the size of the production process (de Neufville 1990). In a Cobb-Douglas function, returns to scale are determined by the sum of the coefficients of the independent variables, if the sum of coefficients is greater than one, then there are increasing returns to scale. For the CobbDouglas model, the sum of coefficients are 3.2 for hours and 1.9 for days, indicating increasing returns to scale. Returns to scale for the translog model show similar results to the Cobb-Douglas model, the sum of coefficients are 3.08 for hours and 1.8 for days.

The marginal product is the change in output due to a unit change in a specific input (de Neufville 1990). If the coefficient $\left(a_{i}\right)$ is greater than one, then the marginal product is increasing, if the coefficient is less than one, marginal product is decreasing. While it may be somewhat of a stretch to view "attitude" as a factor of production, if one does, one sees increasing marginal product for both hours $(a=2.96)$ and days $(a=1.75)$, a better attitude on the part of the employer has an increasing response on the part of the employee in determining the amount of time worked at home. On the other hand, technology alone has a diminishing marginal product for hours $(\mathrm{a}=0.26)$ and days $(a=0.14)$, the first point on the technology scale (the computer) is more important than the second (a printer or modem). However, the technology index composed in this additive manner is somewhat arbitrary. The translog model (Table 11) has quite similar results, though the values of marginal product differ. Attitude has increasing marginal product for hours $(\mathrm{a}=2.18)$ and days $(\mathrm{a}=1.39)$. In the translog model, technology alone was not significant, hence the marginal product was diminishing, and smaller than in the CobbDouglas model, for hours $(\mathrm{a}=0.08)$ and days $(\mathrm{a}=0.06)$. The interaction term was significant, though showed a diminishing marginal product.

The marginal rate of substitution (MRS), the rate at which one input can substitute for another while maintaining constant production, can also be calculated. The marginal rate of substitution is the ratio of the coefficients of two inputs over the ratio of the 
amount of those two inputs. Here, the average value of attitude (0.13) and technology (0.77) are used. In the case of days worked at home as an output, 1 point of attitude is worth 74 times the value of 1 point of technology — but this is determined in part based on how the scales were defined (attitude from $0-1$, technology from 0-4):

$$
\mathrm{MRS}=-(\mathrm{a} 1 / \mathrm{a} 2)
$$

$(\mathrm{X} 1 / \mathrm{X} 2)$

Marginal Rate of Substitution: Attitude for Technology:

$\begin{array}{lcl} & \text { Hours } & \text { Day } \\ \text { Cobb-Douglas } & 67 & 74 \\ \text { Translog } & 161 & 137\end{array}$

note: for the Translog model, the interaction term is not considered in the above table.

However, unless the cost function of employer attitude towards work at home can be determined, it is not possible to use this model to estimate the optimal trade-off for technology and attitude. While it may seem simple to suggest that employers just change their mindset, that mindset is presumably based on perceived costs in lost productivity to the organization caused by working at home. Whether those perceptions are accurate is a separate question from whether they exist. In addition, the costs and benefits of deferred trips to society as a whole would need to be calculated.

\section{CONCLUSIONS}

Technology and work at home are clearly associated. The employer's attitude also matters to a great extent. But what else influences this decision remains unclear. More data are necessary to answer this question.

A related issue concerns whether time spent working at home complements or substitutes for transportation. It is clear that some at-home work is in addition to that in the office, while other at-home work can substitute for a trip to the office-technology and employer attitude influence both of these kinds of work. Future research should analyze this question further with addition data and ideally as a longitudinal study of the how individual behavior changes over the years with their technology acquisition.

An implication of the influence of information technology on travel demand is that it calls into question whether transportation is separable from other aspects of the 
economy in both monetary and activity/time use analysis. This assumption is often made, travel demand models rarely incorporate non-transportation factors except for some macroscopic income indicator. But if communication can substitute for transportation, this aspect needs to be considered.

The model suggests that enabling factors (technology and employer attitude) are both necessary for significant amount of at-home work. Many of the factors which have been suggested as transportation control measures (TCM) may also alter this decision but have not been included. These factors deal principally with the various subsidies for transportation (both roads and transit). While equalizing subsidy within transport may be preferred to unequal subsidies, if transport is still subsidized compared with communications, this will lead to its overconsumption. These subsidies include untaxed parking benefits, infrastructure construction and the lack of accounting for social costs. Similarly, recent revision to the tax code make it more difficult to write-off home offices, which are essential for part-time at-home work.

Further technological advances may increase or decrease the quality of the home as a workplace relative to the office. If the technology at an outside office remains significantly better than at home, little progress towards an increased share of work at home may be made. Technology adoption typically follows an S-curve, with slow adoption initially until a threshold is reached, increasing steadily until some saturation level. Home computers are used by $36 \%$ of the sample. If saturation is $100 \%$, work at home will increase commensurately, but still will not come close to surpassing commuting. Further technological advances including high quality, inexpensive, point to point video conferencing and relative instantaneous transfer of data, will be necessary for that to happen. 


\section{REFERENCES}

Becker, Gary (1965) "A Theory of the Allocation of Time" Economic Journal 75 no 299, Sept. 1965: 493-517.

Bryant, Howard (1994) “Title Wave: Magazine Publishers Discover the Home Computer Market" in Oakland Tribune, Nov. 13, 1994, p.D1, Oakland, CA

de Neufville, Richard (1990) Applied Systems Analysis, McGraw-Hill Publishing Co.

New York

Kumar, Ajay. and Replogle, M. (1992) “Low-Cost Travel Panel Survey” presented at First U.S. Conference for Panels for Transportation Planning, Lake Arrowhead, California Oct. 25-27, 1992

Levinson David and Kumar, Ajay. (1995) "Activity, Travel, and the Allocation of Time" Journal of the American Planning Association, forthcoming 1995

Mokhtarian, Patricia L. (1992) "Telecommuting and Travel: State of the Practice, State of

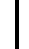

Montgomery County Planning Department. (1993). Evaluation of a Panel Survey Design

$\mid$

Niles, John S. (1994) Beyond Telecommuting: A New Paradigm for the Effect of

Telecommunications on Travel, US Dept. of Energy, Washington DC

Pendyala, Ram M., Konstadinos, G. Goulias, and Ryuichi Kitamura. (1991) "Impact of Telecommuting on Spatial and Temporal Patterns of Household Travel" Transportation 18 (No. 4, 1991) 383-409

Schor, Juliet (1992) The Overworked American, Basic Books New York

U.S. Department of Transportation (1993) Transportation Implication of Telecommuting, US Dept. of Transportation, Washington DC 


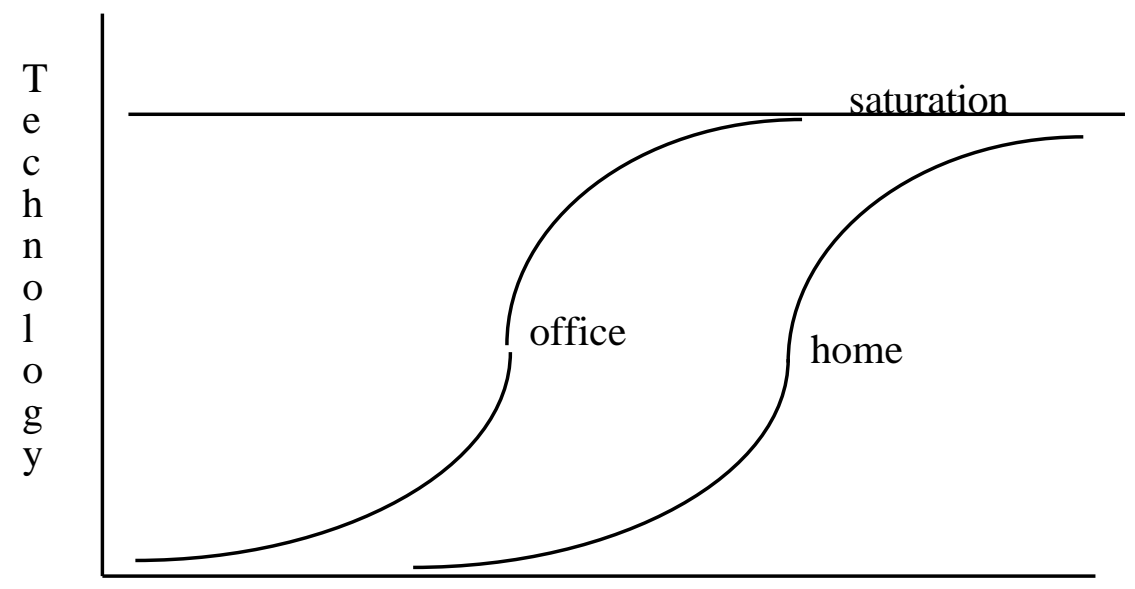

Time --->

FIGURE 1: Office and Home Technology Both Approach Saturation at Equivalent Technology Levels

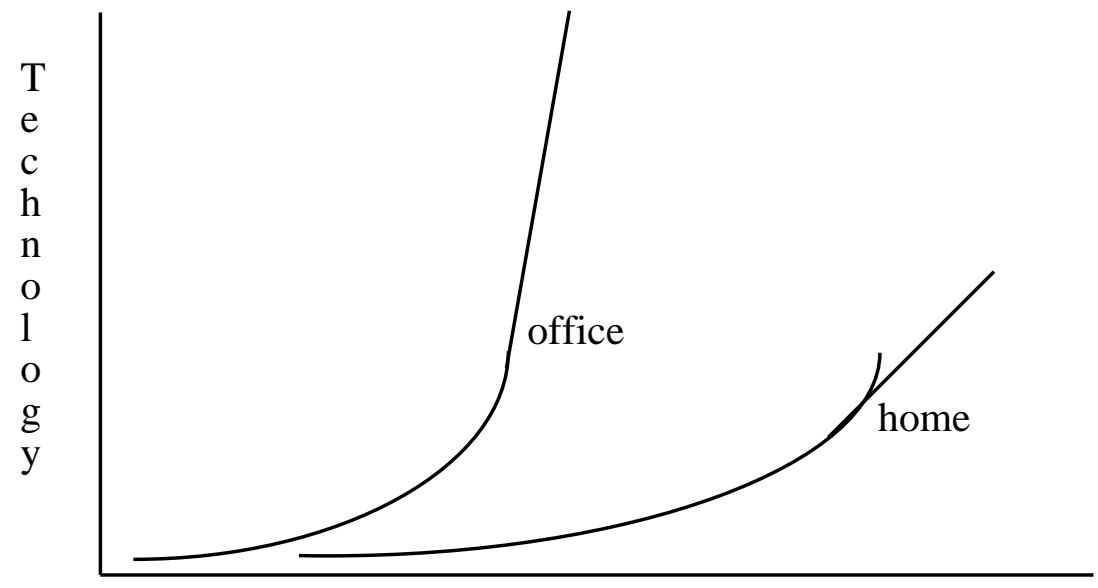

Time --->

FIGURE 2: Office Technology Grows Faster Than Home Technology, and the Advantage of Office Increases at an Accelerating Rate. 
TABLE 1: TECHNOLOGY AND TIME WORKED AT HOME

\begin{tabular}{|lccrr|}
\hline $\begin{array}{l}\text { Equipment } \\
\text { Owned }\end{array}$ & $\begin{array}{r}\text { Hours } \\
\text { Mean }\end{array}$ & $\begin{array}{r}\text { Days } \\
\text { Mean }\end{array}$ & \multicolumn{2}{c|}{ N Share } \\
\hline Computer & 6.9 & 1.4 & 148 & $36 \%$ \\
Printer & 6.3 & 1.4 & 110 & $27 \%$ \\
Fax & 19.7 & 2.7 & 9 & $2 \%$ \\
Modem & 12.4 & 2.4 & 59 & $14 \%$ \\
& & & & \\
TOTAL & 3.1 & 0.7 & 410 & $100 \%$ \\
\hline
\end{tabular}

TABLE 2: TECH INDEX AND TIME WORKED AT HOME

\begin{tabular}{|c|c|c|c|c|c|c|c|c|c|c|}
\hline \multirow{2}{*}{$\begin{array}{l}\text { TECH } \\
\text { Index }\end{array}$} & \multicolumn{6}{|c|}{$\begin{array}{l}\text { Of the Entire Working Population } \\
\text { Hours (per } 2 \text { wk) Days (per } 2 \text { wk.) }\end{array}$} & \multicolumn{4}{|c|}{$\begin{array}{l}\text { Of Those Who Work at Home } \\
\text { Hours/ Day }\end{array}$} \\
\hline & Mean & d. Dev. & Mean & I. Dev. & $\mathrm{N}$ & Share & Mean & Std. Dev. & $\mathrm{N}$ & Share \\
\hline ( & 0.9 & 4.6 & 0.3 & 1.6 & 260 & $63 \%$ & 2.6 & 1.3 & 16 & $27 \%$ \\
\hline 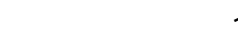 & 2.4 & 4.7 & 0.9 & 1.6 & 27 & $7 \%$ & 3.4 & 2.6 & 7 & $12 \%$ \\
\hline 2 & 5.9 & 20.4 & 1.1 & 2.9 & 75 & $18 \%$ & 5.0 & 5.5 & 17 & $29 \%$ \\
\hline 3 & 8.9 & 17.3 & 1.9 & 3.1 & 43 & $10 \%$ & 4.5 & 3.7 & 16 & $27 \%$ \\
\hline 2 & 26.4 & 31.2 & 9.2 & 3.9 & 5 & $1 \%$ & 6.0 & 3.5 & 3 & $5 \%$ \\
\hline TOTAL & 3.1 & 12.0 & 0.7 & 2.2 & 410 & $100 \%$ & 4.1 & 3.8 & 59 & $100 \%$ \\
\hline
\end{tabular}

TABLE 3: GENDER AND TIME WORKED AT HOME

\begin{tabular}{|c|c|c|c|c|c|c|c|c|c|c|}
\hline \multirow[b]{2}{*}{ Gender } & \multicolumn{6}{|c|}{ Of the Entire Working Population } & \multicolumn{4}{|c|}{$\begin{array}{l}\text { Of Those Who Work at Home } \\
\text { Hours/ Day }\end{array}$} \\
\hline & Mear & d. Dev & Mear & Dev & $\Lambda$ & Share & Mean & Std. Dev. & & Share \\
\hline Female & 3.8 & 14.6 & 0.8 & 2.2 & 206 & $50 \%$ & 4.7 & 4.7 & 33 & $56 \%$ \\
\hline Male & 2.3 & 8.8 & 0.7 & 2.2 & 204 & $50 \%$ & 3.3 & 2.1 & 26 & $44 \%$ \\
\hline TOTAL & 3.1 & 12.0 & 0.7 & 2.2 & 410 & $100 \%$ & 4.1 & 3.8 & 59 & $100 \%$ \\
\hline
\end{tabular}

TABLE 4: VEHICLE OWNERSHIP AND TIME WORKED AT HOME

\begin{tabular}{|c|c|c|c|c|c|c|c|c|c|c|}
\hline Vehicles & \multicolumn{6}{|c|}{$\begin{array}{l}\text { Of the Entire Working Population } \\
\text { Hours (per } 2 \text { wk)| Days (per } 2 \text { wk.) }\end{array}$} & \multicolumn{4}{|c|}{$\begin{array}{l}\text { Of Those Who Work at Home } \\
\text { Hours/ Day }\end{array}$} \\
\hline 0 & 0.0 & 0.0 & 0.0 & 0.0 & 10 & $2 \%$ & 0.0 & 0.0 & 0 & $0 \%$ \\
\hline 1 & 3.4 & 16.3 & 0.6 & 1.9 & 102 & $25 \%$ & 3.4 & 2.5 & 20 & $34 \%$ \\
\hline 2 & 3.0 & 10.3 & 0.8 & 2.4 & 192 & $47 \%$ & 3.4 & 1.5 & 6 & $10 \%$ \\
\hline 3 & 3.1 & 10.2 & 0.7 & 1.8 & 63 & $15 \%$ & 3.4 & 2.4 & 16 & $27 \%$ \\
\hline $4+$ & 3.3 & 13.4 & 0.9 & 3.0 & 42 & $10 \%$ & 5.7 & 6.0 & 17 & $29 \%$ \\
\hline TOTAL & 3.1 & 12.0 & 0.7 & 2.2 & 409 & $100 \%$ & 4.1 & 3.8 & 59 & $100 \%$ \\
\hline
\end{tabular}


TABLE 5: HOUSE TYPE AND TIME WORKED AT HOME

\begin{tabular}{|c|c|c|c|c|c|c|c|c|}
\hline Housing & \multicolumn{4}{|c|}{$\begin{array}{l}\text { Of the Entire Working Population } \\
\text { Hours (per } 2 \text { wk)| Days (per } 2 \text { wk.) }\end{array}$} & \multicolumn{4}{|c|}{$\begin{array}{l}\text { Of Those Who Work at Home } \\
\text { Hours/ Day }\end{array}$} \\
\hline Apt. & $2.8 \quad 11.4$ & $0.7 \quad 2.4$ & 131 & $32 \%$ & 3.7 & 2.2 & 15 & $25 \%$ \\
\hline House & 12.3 & 2.1 & 279 & $68 \%$ & 4.2 & 4.3 & 44 & $75 \%$ \\
\hline TOTAL & 12.0 & 2.2 & 410 & $100 \%$ & 4.1 & 3.8 & 59 & $100 \%$ \\
\hline
\end{tabular}

TABLE 6: EMPLOYER ATTITUDE AND TIME WORKED AT HOME

\begin{tabular}{|c|c|c|c|c|c|c|c|c|c|c|}
\hline \multirow[b]{2}{*}{ Attitude } & \multicolumn{6}{|c|}{ Of the Entire Working Population } & \multicolumn{4}{|c|}{$\begin{array}{l}\text { Of Those Who Work at Home } \\
\text { Hours/ Day }\end{array}$} \\
\hline & Mear & d. Dev. & Mean & I. Dev & $\Lambda$ & Share & Mean & Std. Dev. & & Share \\
\hline Never & 0.4 & 3.1 & 0.2 & 1.2 & 313 & $76 \%$ & 1.9 & 2.2 & 10 & $17 \%$ \\
\hline Sometimes & 7.6 & 14.1 & 2.0 & 3.1 & 82 & $20 \%$ & 4.1 & 4.3 & 34 & $58 \%$ \\
\hline Always & 34.3 & 39.2 & 5.5 & 3.1 & 15 & $4 \%$ & 5.5 & 4.3 & 15 & $25 \%$ \\
\hline TOTAL & 3.1 & 12.0 & 0.7 & 2.2 & 410 & $100 \%$ & 4.1 & 3.8 & 59 & $100 \%$ \\
\hline
\end{tabular}

TABLE 7: EMPLOYMENT SECTOR AND TIME WORKED AT HOME

\begin{tabular}{|c|c|c|c|c|c|c|c|c|c|c|}
\hline \multirow[b]{2}{*}{ Sector } & \multicolumn{6}{|c|}{ Of the Entire Working Population } & \multicolumn{4}{|c|}{$\begin{array}{l}\text { Of Those Who Work at Home } \\
\text { Hours/ Day }\end{array}$} \\
\hline & Mean & d. Dev. & Mean & I. Dev. & $\Lambda$ & Share & Mean & Std. Dev. & $N$ & Share \\
\hline Private & 1.8 & 7.6 & 0.6 & 2.0 & 179 & $44 \%$ & 3.4 & 2.5 & 20 & $34 \%$ \\
\hline Non-Profit & 1.9 & 6.1 & 0.5 & 1.5 & 49 & $12 \%$ & 3.4 & 1.5 & 6 & $10 \%$ \\
\hline Government & 1.6 & 6.2 & 0.5 & 1.9 & 144 & $35 \%$ & 3.4 & 2.4 & 16 & $27 \%$ \\
\hline Self-Employed & 16.7 & 31.4 & 2.8 & 3.8 & 36 & $9 \%$ & 5.7 & 6.0 & 17 & $29 \%$ \\
\hline TOTAL & 3.1 & 12.0 & 0.7 & 2.2 & 408 & $100 \%$ & 4.1 & 3.8 & 59 & $100 \%$ \\
\hline
\end{tabular}


TABLE 8: OLS MODELS OF TIME SPENT WORKING AT HOME

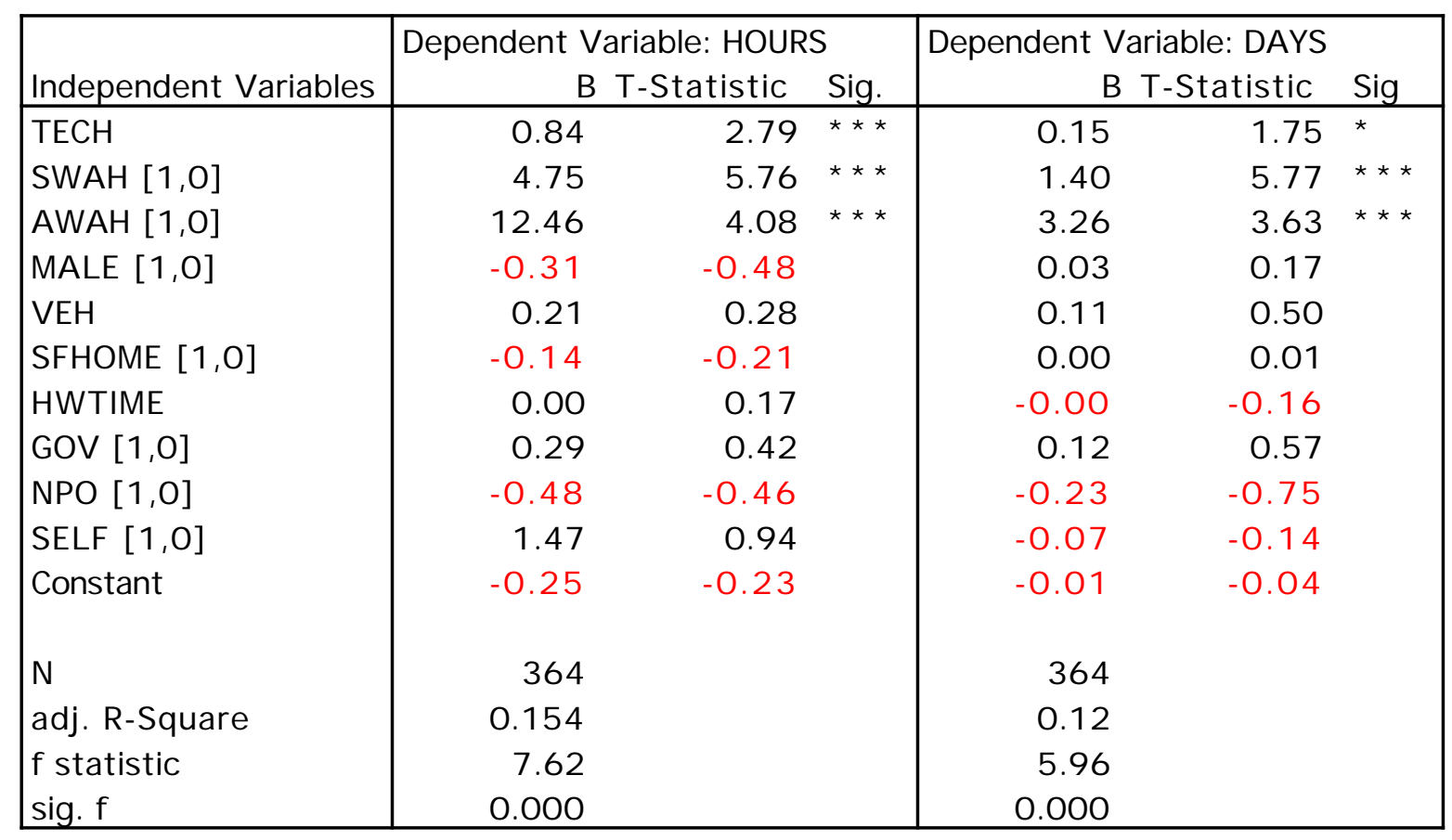

note $*$ indicates significant at $10 \%$ c.i.

$* *$ indicates significant at $5 \%$ c.i.

$* * *$ indicates significant at $1 \%$ c.i. 
TABLE 9: OLS LOG-LINEAR MODELS OF TIME SPENT WORKING AT HOME

\begin{tabular}{|c|c|c|c|c|c|c|}
\hline \multirow[b]{2}{*}{ Independent Variables } & \multicolumn{3}{|c|}{ Dependent Variable:LN(HOURS+1) } & \multicolumn{3}{|c|}{ Dependent Variable:LN(DAYS+1) } \\
\hline & $\mathrm{B}$ & atistic & Sig. & $\mathrm{B}$ & atistic & Sig \\
\hline $\mathrm{LN}(\mathrm{TECH}+1)$ & 0.23 & 3.18 & $* * *$ & 0.12 & 2.55 & $* *$ \\
\hline LN(SWAH+1) $[1,0]$ & 1.13 & 8.07 & $* * *$ & 0.70 & 7.43 & $* * *$ \\
\hline LN(AWAH) $[1,0]$ & 3.21 & 6.22 & $* * *$ & 1.92 & 5.48 & $* * *$ \\
\hline LN(MALE+1) $[1,0]$ & -0.04 & -0.32 & & 0.00 & 0.01 & \\
\hline LN(VEH+1) & 0.03 & 0.18 & & 0.03 & 0.28 & \\
\hline $\mathrm{LN}(\mathrm{SFHOME}+1)[1,0]$ & 0.96 & 0.84 & & 0.06 & 0.73 & \\
\hline LN(HWTIME) & -0.08 & -0.49 & & -0.02 & -0.52 & \\
\hline $\operatorname{LN}(G O V+1)[1,0]$ & 0.08 & 0.65 & & 0.06 & 0.73 & \\
\hline LN(NPO+1) $[1,0]$ & -0.12 & -0.65 & & -0.08 & -0.70 & \\
\hline LN(SELF+1) $[1,0]$ & 0.07 & 0.26 & & -0.03 & -0.17 & \\
\hline Constant & 0.04 & 0.14 & & 0.03 & 0.19 & \\
\hline $\mathrm{N}$ & 364 & & & 364 & & \\
\hline adj. R-Square & 0.264 & & & 0.217 & & \\
\hline f statistic & 14.11 & & & 11.09 & & \\
\hline sig. $f$ & 0.000 & & & 0.000 & & \\
\hline
\end{tabular}

note $*$ indicates significant at $10 \%$ c.i.

$* *$ indicates significant at $5 \%$ c.i.

$* * *$ indicates significant at $1 \%$ c.i. 
TABLE 10: OLS LOG-LINEAR MODELS OF TIME SPENT WORKING AT HOME

\begin{tabular}{|c|c|c|c|c|c|c|}
\hline \multirow{2}{*}{$\begin{array}{l}\text { Independent } \\
\text { Variables } \\
\text { LN }(\text { TECH }+1)\end{array}$} & \multicolumn{2}{|c|}{$\begin{array}{l}\text { Dependent Variable } \\
\text { LN(HOURS+1) } \\
\text { B T-Statistic }\end{array}$} & \multirow{2}{*}{$\frac{\text { Sig. }}{* * *}$} & \multicolumn{2}{|c|}{$\begin{array}{l}\text { Dependent Variable: } \\
\text { LN(DAYS+1) } \\
\text { B T-Statistic }\end{array}$} & \multirow{2}{*}{$\frac{\text { Sig }}{* * *}$} \\
\hline & 0.26 & 3.64 & & 0.14 & 3.06 & \\
\hline LN(CWAH+1) & 2.96 & 14.73 & $* * *$ & 1.75 & 13.47 & $* * *$ \\
\hline Constant & -0.04 & -0.77 & & -0.00 & -0.10 & \\
\hline $\mathrm{N}$ & 409 & & & 409 & & \\
\hline adj. R-Square & 0.418 & & & 0.37 & & \\
\hline f statistic & 147.9 & & & 121.33 & & \\
\hline sig. $f$ & 0.000 & & & 0.000 & & \\
\hline
\end{tabular}

note $*$ indicates significant at $10 \%$ c.i.

$* *$ indicates significant at $5 \% \mathrm{c.i}$.

$* * *$ indicates significant at $1 \%$ c.i.

TABLE 11: OLS TRANSLOG MODELS OF TIME SPENT WORKING AT HOME

\begin{tabular}{|c|c|c|c|c|c|c|}
\hline \multirow{2}{*}{$\begin{array}{l}\text { Independent } \\
\text { Variables } \\
\text { LN }(\text { TECH }+1)\end{array}$} & \multicolumn{3}{|c|}{$\begin{array}{l}\text { Dependent Variable } \\
\text { LN(HOURS }+1)\end{array}$} & \multicolumn{3}{|c|}{$\begin{array}{l}\text { Dependent Variable: } \\
\text { LN(DAYS+1) }\end{array}$} \\
\hline & 0.08 & 0.97 & & 0.06 & 1.07 & \\
\hline $\mathrm{LN}(\mathrm{CWAH}+1)$ & 2.18 & 7.81 & $* * *$ & 1.39 & 7.62 & $* * *$ \\
\hline LN $\left(\mathrm{TECH}^{*} \mathrm{CWAH}+1\right)$ & 0.825 & 3.99 & $* * *$ & 0.3828 & 2.834 & $* * *$ \\
\hline Constant & -0.04 & -0.77 & & -0.00 & -0.10 & \\
\hline $\mathrm{N}$ & 409 & & & 409 & & \\
\hline adj. R-Square & 0.44 & & & 0.38 & & \\
\hline f statistic & 107.5 & & & 84.96 & & \\
\hline sig. $f$ & 0.000 & & & 0.000 & & \\
\hline
\end{tabular}

note $*$ indicates significant at $10 \%$ c.i.

** indicates significant at $5 \%$ c.i.

$* * *$ indicates significant at $1 \%$ c.i. 